\title{
Large area high efficiency broad bandwidth 800 nm dielectric gratings for high energy laser pulse compression
}

\author{
D. H. Martz ${ }^{1}$, H. T. Nguyen ${ }^{2}$, D. Patel ${ }^{1}$, J. A. Britten ${ }^{2}$, D. Alessi ${ }^{1}$, E. Krous ${ }^{1}$, Y. Wang ${ }^{1}$, \\ M. A. Larotonda ${ }^{1}$, J. George ${ }^{3}$, B. Knollenberg ${ }^{3}$, B. M. Luther ${ }^{1}$, J. J. Rocca ${ }^{1}$ and

\section{S. Menoni ${ }^{1}$} \\ ${ }^{I}$ NSF ERC for Extreme Ultraviolet Science and Technology, Colorado State University, Fort Collins, CO U.S.A. \\ ${ }^{2}$ Photon Science and Applications Program, National Ignition Facility Programs Directorate, Lawrence Livermore \\ National Laboratory, Livermore CA 94550 U.S.A. \\ ${ }^{3}$ Veeco Process Equipment Inc., Fort Collins, CO 80525 U.S.A. \\ *Dale.Martz@rams.colostate.edu
}

\begin{abstract}
We have demonstrated broad bandwidth large area $(229 \mathrm{~mm} \mathrm{x}$ $114 \mathrm{~mm}$ ) multilayer dielectric diffraction gratings for the efficient compression of high energy $800 \mathrm{~nm}$ laser pulses at high average power. The gratings are etched in the top layers of an aperiodic $\left(\mathrm{Nb}_{0.5} \mathrm{Ta}_{0.5}\right)_{2} \mathrm{O}_{5}-\mathrm{SiO}_{2}$ multilayer coating deposited by ion beam sputtering. The mean efficiency of the grating across the area is better than $97 \%$ at the center wavelength and remains above $96 \%$ at wavelengths between $820 \mathrm{~nm}$ and $780 \mathrm{~nm}$. The gratings were used to compress $5.5 \mathrm{~J}$ pulses from a Ti:sapphire laser with an efficiency above 80 percent.

(C) 2009 Optical Society of America

OCIS codes: (050.0050) Diffraction and gratings; (050.1950) Diffraction gratings; (050.2770) Gratings; (130.3060) Infrared; (140.0140) Lasers and laser optics; (140.3330) Laser damage; (310.1860) Deposition and fabrication; (320.5520) Pulse compression.
\end{abstract}

\section{References and links}

1. E. B. Treacy, “Optical Pulse Compression With Diffraction Gratings," IEEE J. Quantum Electron. 5(9), 454-458 (1969).

2. D. Strickland, and G. Mourou, "Compression of amplified chirped optical pulses," Opt. Commun. 56(3), 219221 (1985).

3. M. D. Perry, D. Pennington, B. C. Stuart, G. Tietbohl, J. A. Britten, C. Brown, S. Herman, B. Golick, M. Kartz, J. Miller, H. T. Powell, M. Vergino, and V. Yanovsky, "Petawatt laser pulses," Opt. Lett. 24(3), 160-162 (1999).

4. C. B. Edwards, R. M. Allott, J. L. Collier, C. N. Danson, M. H. R. Hutchinson, D. Neely, and B. E. Wyborn, "Vulcan upgrade: a petawatt laser facility for experiments at 10^21 Wcm^-2," in ECLIM 2000: 26th European Conference on Laser Interaction with Matter (2001), pp. 63-69.

5. Y. Kitagawa, H. Fujita, R. Kodama, H. Yoshida, S. Matsuo, T. Jitsuno, T. Kawasaki, H. Kitamura, T. Kanabe, S. Sakabe, K. Shigemori, N. Miyanaga, and Y. Izawa, "Prepulse-Free Petawatt Laser for a Fast Ignitor," IEEE J. Quantum Electron. 40(3), 281-293 (2004).

6. A. S. Svakhin, V. A. Sychugov, and A. E. Tikhomirov, "Efficient diffraction elements for TE-polarized waves," Sov. Phys. Tech. Phys. 36, 1038-1040 (1991).

7. M. D. Perry, R. D. Boyd, J. A. Britten, D. Decker, B. W. Shore, C. Shannon, and E. Shults, "High-efficiency multilayer dielectric diffraction gratings," Opt. Lett. 20(8), 940-942 (1995).

8. J. A. Britten, W. A. Molander, A. M. Komashko, and C. P. Barty, "Multilayer dielectric gratings for petawattclass laser systems," in Laser-Induced Damage in Optical Materials: 2003, H. Guenther, N. Kaiser, K. L. Lewis, M. J. Soileau, and C. J. Stolz, eds. (SPIE, 2004), pp. 1-7.

9. F. Canova, R. Clady, J. P. Chambaret, M. Flury, S. Tonchev, R. Fechner, and O. Parriaux, "High-efficiency, broad band, high-damage threshold high-index gratings for femtosecond pulse compression," Opt. Express 15(23), 15324-15334 (2007).

10. P. P. Lu, K.-X. Sun, R. L. Byer, J. A. Britten, H. T. Nguyen, J. D. Nissen, C. C. Larson, M. D. Aasen, T. C. Carlson, and C. R. Hoaglan, "Precise diffraction efficiency measurements of large-area greater-than-99\%efficient dielectric gratings at the Littrow angle," Opt. Lett. 34(11), 1708-1710 (2009).

11. J. Neauport, E. Lavastre, G. Razé, G. Dupuy, N. Bonod, M. Balas, G. de Villele, J. Flamand, S. Kaladgew, and F. Desserouer, "Effect of electric field on laser induced damage threshold of multilayer dielectric gratings," Opt. Express 15(19), 12508-12522 (2007).

12. J. J. Rocca, Y. Wang, M. A. Larotonda, B. M. Luther, M. Berrill, and D. Alessi, "Saturated $13.2 \mathrm{~nm}$ highrepetition-rate laser in nickellike cadmium," Opt. Lett. 30(19), 2581-2583 (2005).

\#119727 - \$15.00 USD Received 13 Nov 2009; revised 9 Dec 2009; accepted 10 Dec 2009; published 11 Dec 2009 
13. Y. Wang, M. Larotonda, B. Luther, D. Alessi, M. Berrill, V. Shlyaptsev, and J. Rocca, "Demonstration of highrepetition-rate tabletop soft-x-ray lasers with saturated output at wavelengths down to $13.9 \mathrm{~nm}$ and gain down to 10.9nm,’ Phys. Rev. A 72(5), 053807 (2005).

14. B. M. Luther, Y. Wang, M. A. Larotonda, D. Alessi, M. Berrill, M. C. Marconi, J. J. Rocca, and V. N. Shlyaptsev, "Saturated high-repetition-rate 18.9-nm tabletop laser in nickellike molybdenum," Opt. Lett. 30(2), 165-167 (2005).

\section{Introduction}

The grating compressor [1] is one of the most critical components of a high power chirped pulse amplification (CPA) laser system [2]. Requirements for the diffraction gratings include: high diffraction efficiency, high damage threshold, and often the ability to withstand high average powers. Until recently, CPA laser systems have almost exclusively made use of metallic diffraction gratings, in which the diffractive structure is typically coated with a thin gold film. These gold-coated pulse compression gratings have allowed the implementation of a number of high power laser systems around the world [3-5]. An all-dielectric grating alternative was first proposed in 1991 as a possible solution to improve throughput, increase the damage threshold and maximize average power operation [6]. Moreover, dielectric gratings are less prone to experience the degradation that is frequently observed in gold coated gratings. Since then, the fabrication method pioneered at Lawrence Livermore National Laboratory has allowed the production of very large area multilayer dielectric (MLD) gratings operating at a centered wavelength $\lambda=1 \mu \mathrm{m}$ with all the advantages listed above $[7,8]$. However, it has been difficult to produce a dielectric grating design for pulse compression at $\lambda$ $=800 \mathrm{~nm}$. Recently, results from $\lambda=800 \mathrm{~nm}$ all-dielectric $\mathrm{HfO}_{2}-\mathrm{SiO}_{2}$ gratings and metaldielectric gratings manufactured in $25 \mathrm{~mm}$ diameter substrates have been reported [9]. The dielectric gratings were reported to have a diffraction efficiency of 96 percent over a bandwidth of $38 \mathrm{~nm}$, and a high damage threshold.

Hereafter we present results of the development and fabrication of broad bandwidth large area MLD gratings for the compression of Ti:sapphire laser pulses based on a $\left(\mathrm{Nb}_{0.5} \mathrm{Ta}_{0.5}\right)_{2} \mathrm{O}_{5^{-}}$ $\mathrm{SiO}_{2}$ multilayer coating. The measured -1 st order diffraction efficiency of these MLD gratings is better than $97 \%$ at $800 \mathrm{~nm}$ and above $96 \%$ over a spectral bandwidth of at least 40 $\mathrm{nm}$. The gratings were used to compress $5.5 \mathrm{~J}$ pulses from a Ti:sapphire laser with an efficiency more than 80 percent.

\section{Grating design}

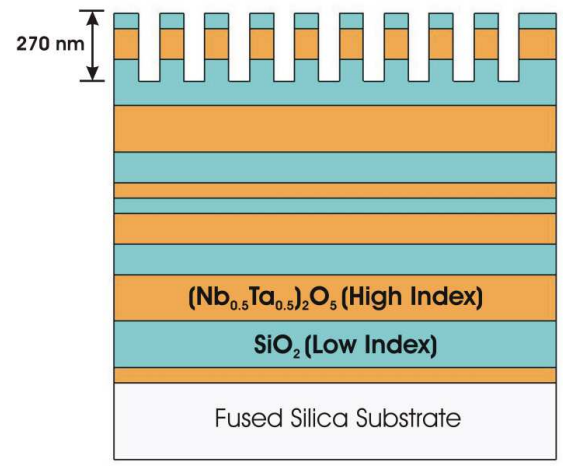

Fig. 1. Schematic diagram of a dielectric multilayer deposited on top of a fused silica substrate. The reflective multilayer stack has 20 layers.

The grating was designed to have a line density of 1740 lines/mm, giving a Littrow angle of 44.1 degrees at a wavelength of $800 \mathrm{~nm}$, while allowing for a large acceptance angle of at least 10 degrees from Littrow. This corresponds to input and output operating angles of $~ 35$ and $\sim 55$ degrees respectively. The grating was designed to have maximum diffraction

\#119727 - \$15.00 USD Received 13 Nov 2009; revised 9 Dec 2009; accepted 10 Dec 2009; published 11 Dec 2009 
efficiency at a center wavelength of $800 \mathrm{~nm}$ and a bandwidth acceptance of more than $60 \mathrm{~nm}$. The grating design consists of a MLD high reflectance interference coating with grooves etched into the top layers (Fig. 1). The high reflector (HR) is created by an asymmetric dielectric stack with 20 alternating layers of high $\left(\mathrm{Nb}_{0.5} \mathrm{Ta}_{0.5}\right)_{2} \mathrm{O}_{5}$ and low $\mathrm{SiO}_{2}$ index materials. This material combination was selected because it offers large index contrast and the possibility of designing a large bandwidth grating at $800 \mathrm{~nm}$. The grooves are etched to be $270 \mathrm{~nm}$ deep, and reside in the top three layers rather than confined to the low index capping layer, which is a common practice.

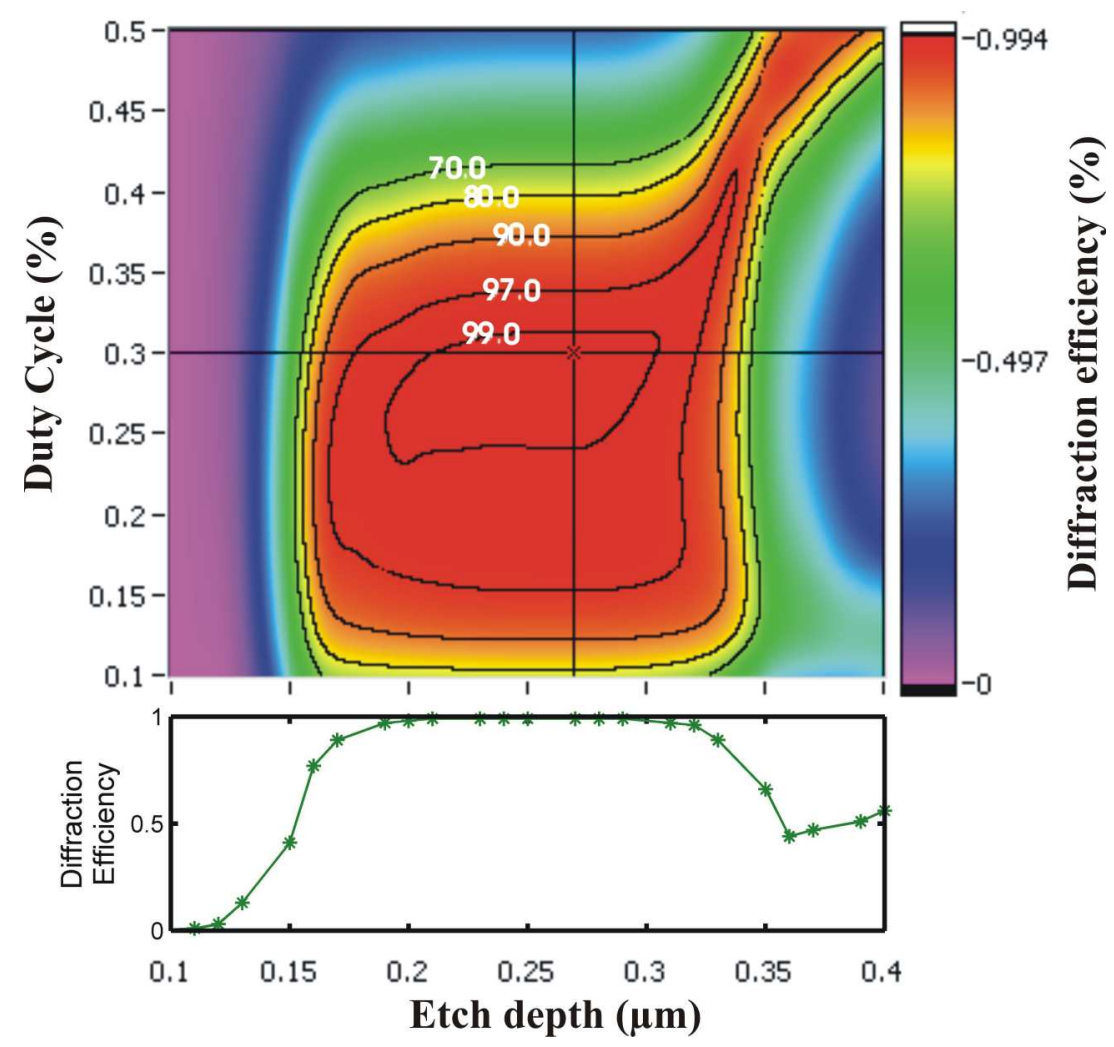

Fig. 2. Simulated diffraction efficiency map of the -1 st order of an $800 \mathrm{~nm}$ grating operating at an angle of 38 degrees as a function of etch depth and duty cycle of the line pattern. The contours indicate constant diffraction efficiency. The cut shows the variation of diffraction efficiency versus etch depth at the optimum, $30 \%$ duty cycle.

Figure 2 shows the simulated -1 st order diffraction efficiency of the MLD grating operating at an angle of incidence of 38 degrees computed as a function of the groove depth and the linewidth/separation ratio (duty cycle) of the line pattern. Both parameters affect the diffraction efficiency significantly. The crossed lines in Fig. 2 identify the combination of parameters selected for fabrication, a groove depth of $270 \mathrm{~nm}$ and a duty cycle of $30 \%$, and the corresponding simulated diffraction efficiency. Figure 3 illustrates the sensitivity of the MLD diffraction efficiency to variations of a few percent to the duty cycle and groove depth. These effects make the manufacturing of MLD gratings very challenging if the process is not well controlled. 


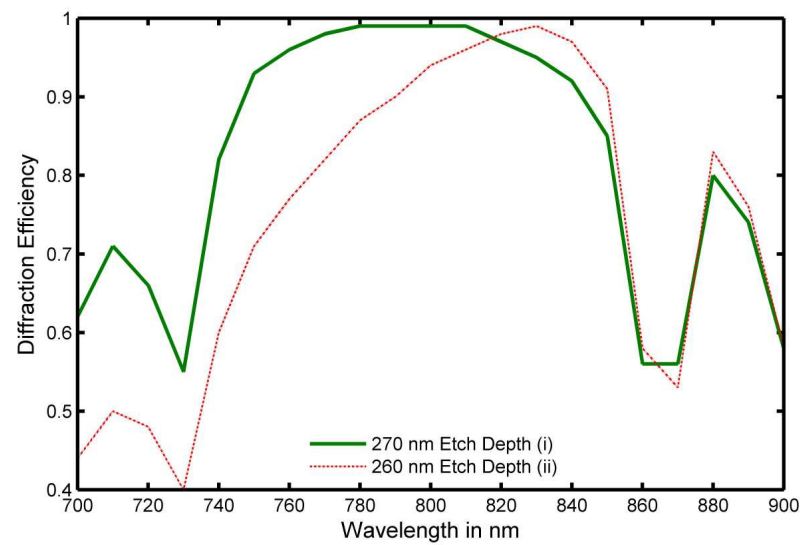

Fig. 3. Simulated diffraction efficiency of the -1 st order of an $800 \mathrm{~nm}$ grating operating at an angle of 38 degrees. (i) Optimum $270 \mathrm{~nm}$ groove depth with a $30 \%$ duty cycle (ii) $260 \mathrm{~nm}$ groove depth with a $36 \%$ duty cycle.

\section{High reflector design, fabrication and testing}

The MLD stack consists of sequential layers of $\mathrm{SiO}_{2}$ and $\left(\mathrm{Nb}_{0.5} \mathrm{Ta}_{0.5}\right)_{2} \mathrm{O}_{5}$ with layer thickness varying from a minimum of $40 \mathrm{~nm}$ (thickness of the low index capping layer) to a maximum of $300 \mathrm{~nm}$. The design offers $99.99 \%$ reflectivity at a centered wavelength of $800 \mathrm{~nm}$. The reflection at a wavelength of $413 \mathrm{~nm}$, corresponding to the krypton ion laser used in the lithographic process, is less than 10 percent. This requirement ensures minimum degradation of the holographic line pattern due to back-reflections. The MLD stacks were deposited by ion beam sputtering using a Veeco Spector ion beam deposition system equipped with a planetary apparatus capable to accommodate large substrates. The Spector ${ }^{\circledR}$ platform utilized a $16 \mathrm{~cm}$ RF deposition source and a $12 \mathrm{~cm}$ assist source which provided substrate cleaning and thin film stoichiometry control. Stringent control of layer thicknesses during deposition was required to match the design and maintain a coating reflectivity uniformity of $<1 \%$ centered at $800 \mathrm{~nm}$ across the entire substrate area.

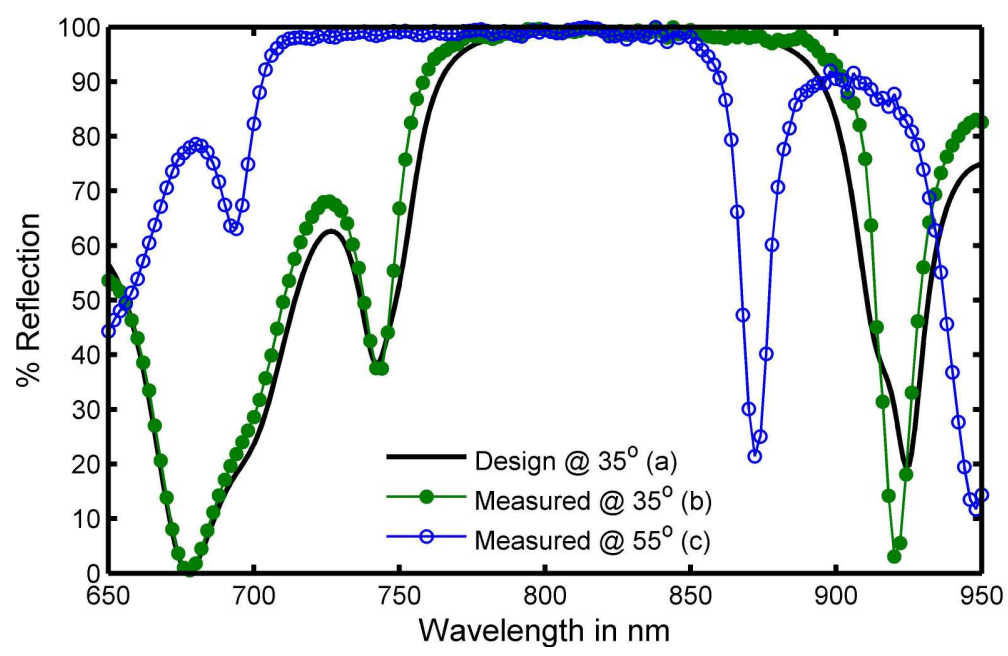

Fig. 4. S-polarization spectral response of the asymmetric 20 layer MLD high reflector. Simulated (a) reflection at 35 degrees, measured reflection at 35 (b) and 55 (c) degrees.

The MLD stack was deposited onto $229 \mathrm{~mm}$ x $114 \mathrm{~mm}$ fused silica slabs. The measured Spolarization reflection of the MLD coatings obtained by elipsometery is shown in Fig. 4. The

\#119727 - \$15.00 USD Received 13 Nov 2009; revised 9 Dec 2009; accepted 10 Dec 2009; published 11 Dec 2009 (C) 2009 OSA

21 December 2009 / Vol. 17, No. 26 / OPTICS EXPRESS 23812 
plot compares the designed reflectivity at 35 degrees incidence angle (a) with the measured response (b). The agreement highlights the reliable layer thickness control obtained with the dual ion beam deposition system. The plot also compares the measured reflectance of the MLD stack at incidence angles of 35 (b) and 55 (c) degrees respectively, showing that the HR interference coating offers a $100 \mathrm{~nm}$ spectral window centered around $800 \mathrm{~nm}$.

\section{Grating fabrication and performance}

The grating structure was printed into the multilayer dielectric coating by interferometric photolithography. A layer of photoresist deposited on top of the multilayer stack was exposed using a holographic exposure tool based on the $\lambda=413 \mathrm{~nm}$ line of a krypton ion laser. Following exposure, the substrates were baked to harden the resist after which the fused silica slabs were inserted into a reactive ion-beam etching (RIBE) tool capable of etching submicron features into substrates. Etching was carried out with an etching gas mix of $\mathrm{CHF}_{3}, \mathrm{Ar}$ and $\mathrm{O}_{2}$ using the same protocol described in [8] for the fabrication of $1 \mu \mathrm{m}$ MLD gratings. As mentioned above, the groove depth has a critical effect on the diffraction efficiency, requiring accurate control of the etching process across the entire grating surface.

The efficiency of the MLD gratings was measured over the entire area of the fused silica slab using the scanning photometry tool described in [10]. Figure 5 shows a map of the -1 st order diffraction efficiency of a completed grating measured at a wavelength of $800 \mathrm{~nm}$ and at an incident angle of 38 degrees. A diffraction efficiency of $97.3 \%$ with a standard deviation of $0.3 \%$ was measured across the full slab area.
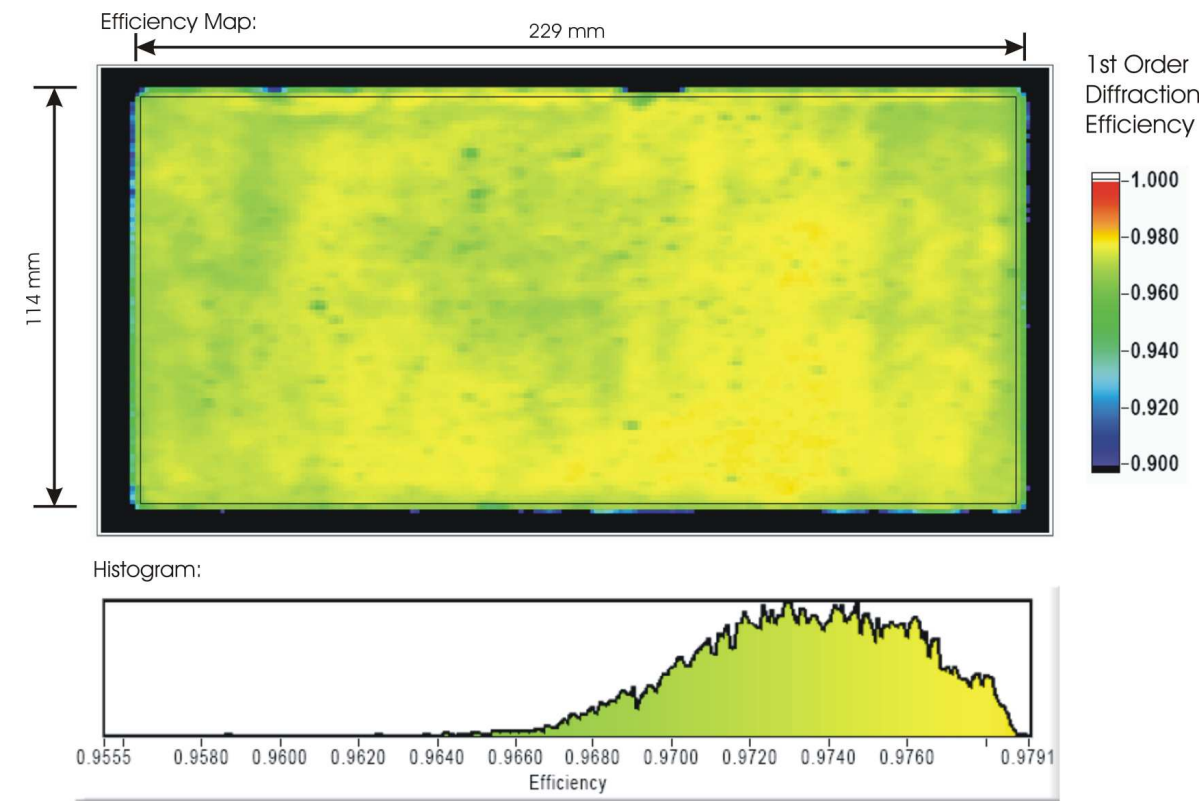

Fig. 5. Map of the -1 st order diffraction efficiency of a $229 \mathrm{~mm}$ x $114 \mathrm{~mm}$ grating measured at an operating angle of 38 degrees at a wavelength of $800 \mathrm{~nm}$. The mean efficiency is $97.3 \%$ with a standard deviation of $0.3 \%$. The histogram shows the distribution of diffraction efficiency over the entire grating area.

The mean diffraction efficiency remained above $96 \%$ for wavelengths between $820 \mathrm{~nm}$ and $780 \mathrm{~nm}$. Figure 6 compares the measured diffraction efficiency with the design. The design has a large bandwidth acceptance of over $70 \mathrm{~nm}$ at $95 \%-1$ st order diffraction efficiency (>90 $\mathrm{nm}$ at $90 \%-1$ st order diffraction efficiency). The measured mean diffraction efficiencies show that the grating performs as expected, and furthermore, that the manufacturing process has high reproducibility. This is demonstrated in Table 1 which displays the measured mean diffraction efficiency values of the -1 st order at $\lambda=800 \mathrm{~nm}$ for 
four different gratings. The values of the diffraction efficiency averaged over a $40 \mathrm{~nm}$ bandwidth centered at $800 \mathrm{~nm}$ are also shown.

Table 1. Measured -1st order diffraction efficiencies for four different 229 mm x 114 mm gratings $(\%)$

\begin{tabular}{|c|c|c|c|c|c|c|c|}
\hline & \multicolumn{2}{|c|}{$780 \mathrm{~nm}$} & \multicolumn{2}{c|}{$800 \mathrm{~nm}$} & \multicolumn{2}{c|}{$820 \mathrm{~nm}$} & $\begin{array}{c}\text { Averaged } \\
\text { Diffraction } \\
\text { Efficiencies } \\
780-820 \mathrm{~nm}\end{array}$ \\
\hline & Mean & RMS & Mean & RMS & Mean & RMS & $\mathbf{9 6 . 9}$ \\
\hline 1 & 96.8 & 0.9 & 97.8 & 0.2 & 96.2 & 0.5 & $\mathbf{9 6 . 1}$ \\
\hline 2 & 97.2 & 0.6 & 96.7 & 0.3 & 94.5 & 0.5 & $\mathbf{9 6 . 0}$ \\
\hline 3 & 96.8 & 0.7 & 97.3 & 0.3 & 93.9 & 0.7 & $\mathbf{9 5 . 3}$ \\
\hline 4 & 97.8 & 0.2 & 96.1 & 0.7 & 91.9 & 1.6 & \\
\hline
\end{tabular}

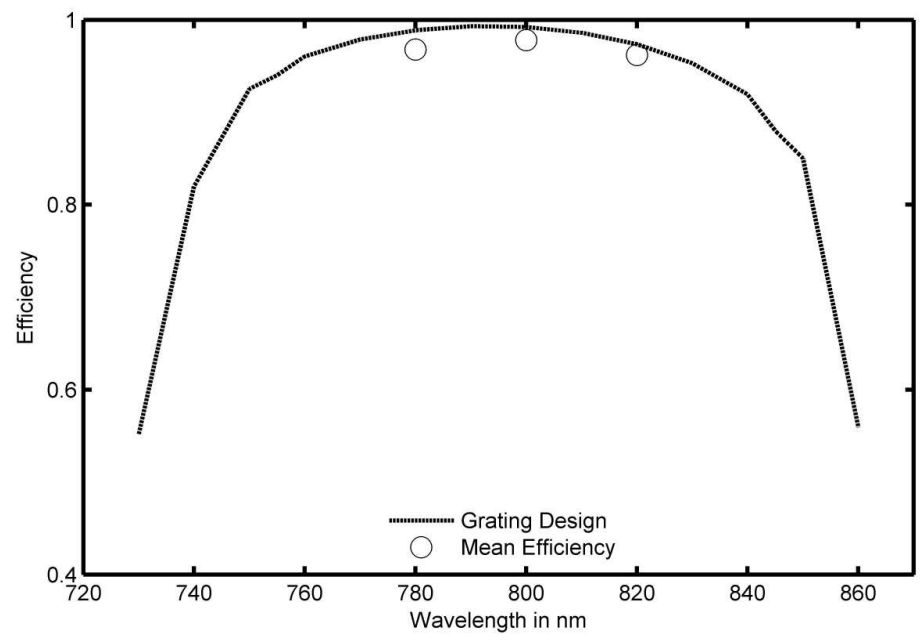

Fig. 6. Diffraction efficiency of the -1 st order of an $800 \mathrm{~nm}$ grating operating at 38 degrees: The dotted line shows the design simulation of the diffracted light with a $270 \mathrm{~nm}$ groove depth. The circles are the measured mean efficiencies of the fabricated $229 \mathrm{~mm}$ x $114 \mathrm{~mm}$ grating.

\section{Damage testing of the MLD high reflector and grating}

The single-pulse laser damage threshold of the MLD interference coatings and of the completed grating were measured for different laser pulse lengths by adjusting the pulsewidth of a CPA $10 \mathrm{~Hz}$ Ti:Sapphire laser. The setup used for the damage threshold measurement is shown schematically in Fig. 7. Two polarizing beam splitters and a waveplate were used to control the laser pulse energy. The samples were irradiated at an operating angle of 55 degrees with an S-polarized beam focused into a $\sim 200 \mu \mathrm{m}$ diameter spot by a $3 \mathrm{~m}$ focal length lens. The beam fluence on the sample was determined by simultaneously monitoring the intensity profile and the laser pulse energy using a high transmission beam splitter. The energy of every shot was monitored with a Gentec TPM-300 power meter and the intensity profile was monitored by imaging the laser beam onto a CCD camera with a $100 \mathrm{~mm}$ focal length lens. To determine when damage occurs, the surface of the sample was monitored using a second imaging system composed of a $100 \mathrm{~mm}$ focal length imaging lens and a camera. The surface of the sample was illuminated with the light emanating from an optical fiber bundle to increasing the visibility of the irradiated area. The damage threshold of the multilayer coating was measured to decrease from $7+/-0.5 \mathrm{~J} / \mathrm{cm}^{2}$ for $120 \mathrm{ps}$ pulses to $0.4+/-0.02 \mathrm{~J} / \mathrm{cm}^{2}$ for 120 fs pulses with a value of $0.87+/-0.2 \mathrm{~J} / \mathrm{cm}^{2}$ for 1 ps pulses.

\#119727 - \$15.00 USD Received 13 Nov 2009; revised 9 Dec 2009; accepted 10 Dec 2009; published 11 Dec 2009 (C) 2009 OSA 


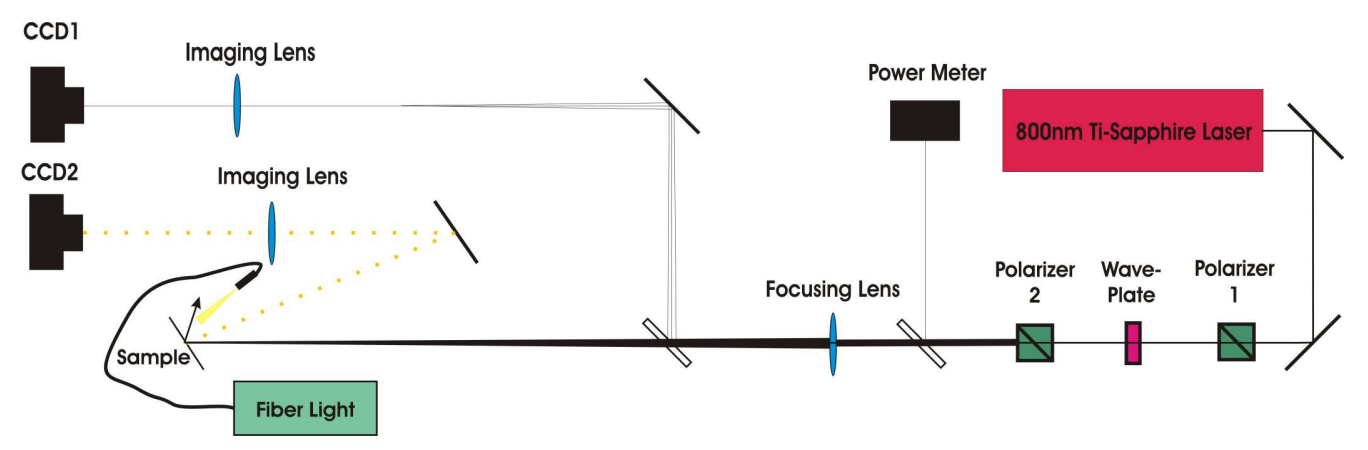

Fig. 7. Schematic diagram of the setup used to determine damage threshold.

Damage threshold measurements were also performed on the finished MLD grating structures using $50 \mathrm{~mm}$ diameter ridealong samples. The measured damage threshold using the S-polarized Ti:sapphire beam with an incident angle of 55 degrees varied from $1.76+/-$ $0.1 \mathrm{~J} / \mathrm{cm}^{2}$, down to $0.18+/-0.02 \mathrm{~J} / \mathrm{cm}^{2}$ for pulsewidths ranging from $120 \mathrm{ps}$ down to $120 \mathrm{fs}$ respectively. Table 2 summarizes the results of the measurements. The damage threshold of the gratings for 1 ps pulses is $\sim 2.4$ times lower than that of the MLD interference coating. This is due to increased electric field at the edges of the grating ridges $[8,11]$.

Table 2. Damage threshold of MLD stack and MLD gratings at 55 degrees

\begin{tabular}{|c|c|c|c|c|}
\hline & $120 \mathrm{fs}$ & $1 \mathrm{ps}$ & $10 \mathrm{ps}$ & $120 \mathrm{ps}$ \\
\hline MLD Stack $\left(\mathrm{J} / \mathrm{cm}^{2}\right)$ & $\mathbf{0 . 4 0}+/ \mathbf{- 0 . 0 2}$ & $\mathbf{0 . 8 7}+/-\mathbf{0 . 0 6}$ & $\mathbf{2 . 3 + / - 0 . 2}$ & $\mathbf{7 . 0 7}+/-\mathbf{0 . 5}$ \\
\hline MLD Grating $\left(\mathrm{J} / \mathrm{cm}^{2}\right)$ & $\mathbf{0 . 1 8}+/ \mathbf{- 0 . 0 2}$ & $\mathbf{0 . 3 7 + / - 0 . 0 2}$ & $\mathbf{0 . 7 4}+/-\mathbf{0 . 0 4}$ & $\mathbf{1 . 7 6}+/-\mathbf{0 . 1}$ \\
\hline
\end{tabular}

\section{Pulse compression results}

A set of four (229 mm x $114 \mathrm{~mm}$ ) MLD gratings were used to setup a double pass vacuum compressor for the compression of $5.5 \mathrm{~J}$ pulses from a Ti:sapphire laser. The photograph displayed in Fig. 8 shows a partial view of the compressor in which two of the gratings are visible. The compressor was configured to compress 220 ps Ti:sapphire pulses that had been chirped by a grating stretcher implemented using a MLD grating produced in the same run. In this configuration the grating compressor has a bandwidth acceptance of $60 \mathrm{~nm}$ for a beam diameter of $96 \mathrm{~mm}$. Although the measured spectral performance data shows the gratings will support the compression of $25 \mathrm{fs}$ pulses, the separation of the gratings was set to generate pulses of 3-6 picosecond durations which are optimum for the excitation of transient collisional soft $\mathrm{x}$-ray lasers in several elements [12-14]. The throughput of the compressor was measured to be greater than $80 \%$. We have used the gratings to compress input pulses of $5.5 \mathrm{~J}$ at repetition rates up to $2.5 \mathrm{~Hz}$ for several months without observing any grating degradation. Interferometry of the grating surface, subjected to several times this average fluence detected no measurable deformation, showing these MLD gratings are suited for high average power applications. This is in contrast with a previous setup that made use of gold coated replica gratings where we observed wavefront distortion due to thermal deformation at similar fluences. In another application we used smaller gratings made in the same fabrication process to compress pulses to pulsewidths below $70 \mathrm{fs}$, verifying that the MLD gratings have the bandwidth necessary for high average power femtosecond laser applications.

\#119727 - \$15.00 USD Received 13 Nov 2009; revised 9 Dec 2009; accepted 10 Dec 2009; published 11 Dec 2009 (C) 2009 OSA 


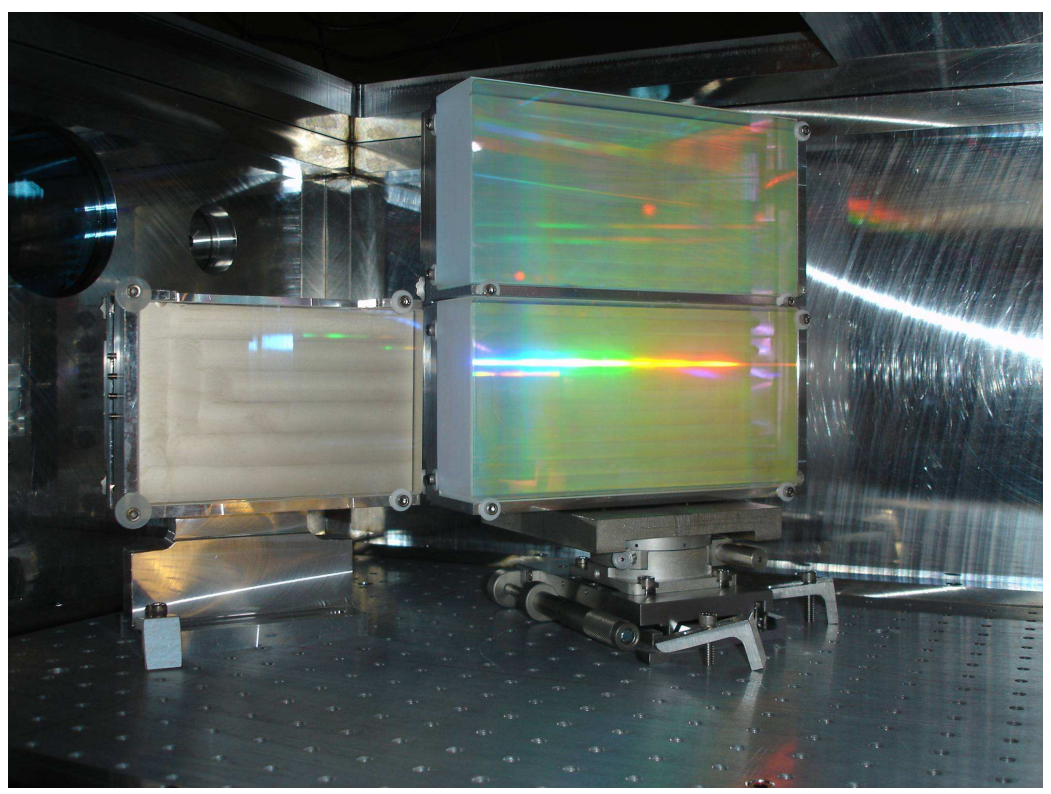

Fig. 8. Photograph of two $229 \mathrm{~mm} \times 114 \mathrm{~mm}$ dielectric gratings that are part of a vacuum pulse compressor for high energy Ti:sapphire laser pulses.

\section{Conclusions}

We have developed durable broad bandwidth high efficiency large area $\lambda=800 \mathrm{~nm}$ multilayer dielectric diffraction gratings for pulse compression of high energy Ti-Sapphire laser pulses at high average power. The MLD gratings have a mean efficiency that is better than $97 \%$ at the center wavelength and remains above $96 \%$ at wavelengths of $820 \mathrm{~nm}$ and $780 \mathrm{~nm}$. The gratings were employed in the implementation of a high energy vacuum compressor with a throughput greater than $80 \%$. The compressor was used to generate picosecond duration Ti:sapphire laser pulses with an energy $\sim 4.5 \mathrm{~J}$ at a repetition rate of up to $2.5 \mathrm{~Hz}$ for several months without signs of degradation.

\section{Acknowledgements}

This work was supported by the NSF Center for Extreme Ultraviolet Science and Technology under NSF Award Number EEC-0310717 and the United States Department of Energy by the Lawrence Livermore National Laboratory under contract number DE-AC52-07NA27344.

\#119727 - \$15.00 USD Received 13 Nov 2009; revised 9 Dec 2009; accepted 10 Dec 2009; published 11 Dec 2009 